\title{
Tiresias era ciego y clarividente: ¿Podría haber adivinado lo que sucedió en 2020 ?
}

\author{
Tiresias was blind as well as clairvoyant: ¿Could he had foreseen what \\ hapenned in 2020 ?
}

Tito Tricot. Universidad Alberto Hurtado; tricot18@gmail.com

\begin{tabular}{|c|c|}
\hline Historia editorial & Resumen \\
\hline Recibido: 23/12/2021 & El texto tiene como objetivo reflexionar acerca de algunos eventos los que, \\
\hline $\begin{array}{l}\text { Primera revisión: } \\
23 / 12 / 2021\end{array}$ & $\begin{array}{l}\text { a su vez, son constitutivos de problemáticas significativas en las relaciones } \\
\text { chileno-mapuche actuales. En particular, nos remitimos a la represión }\end{array}$ \\
\hline Aceptado: 27/12/2021 & sistemática que se ha entronizado en el Wallmapu, al entramado de Poder y \\
\hline Publicado: 27/12/2012 & $\begin{array}{l}\text { contra-Poder que surgen en torno a las distintas estrategias adoptadas por } \\
\text { el movimiento mapuche autonomista, engarzando los conceptos y prácti- } \\
\text { cas de autonomía, libredeterminación y plurinacionalidad. Y, vinculado con }\end{array}$ \\
\hline $\begin{array}{l}\text { Palabras clave } \\
\text { Enemigo interno } \\
\text { Contra-Poder }\end{array}$ & $\begin{array}{l}\text { todo lo anterior, la Convención Constitucional y, más específicamente, los } \\
\text { escaños reservados para los pueblos originarios. Como toda acuarela, no } \\
\text { pretende ser irisada en profundidad. }\end{array}$ \\
\hline
\end{tabular}

Escaños reservados

Autonomía

Plurinacionalidad

\section{Abstract}

\section{Keywords}

Internal Enemy

Counter-Power

Reserved Indigenous

Seats

Autonomy

Plurinationality
The text seeks to reflect upon certain key events which, at the same time, constitute an expression of profound problems that affect current ChileanMapuche relationships. Most specifically, we will refer to the systematic repression that has fallen upon the Wallmapu; the Architecture of Power and Counter-Power that has emerged within this context. Also, the different strategies adopted by the Autonomist Mapuche Movement, linking the concepts and praxis of autonomy, self-determination and plurinationality. Finally, related with the above, we will briefly analyze the Constitutional Convention, particularly regarding the Reserved Seats for Indigenous Peoples. As in any watercolour, the text does not pretend to be painted in depth

Tricot, T. (2021). Tiresias era ciego y clarividente: ¿Podría haber adivinado lo que sucedió en 2020?, Anuario del Conflicto Social,12, e- 37731. https://doi.org/10.1344/ACS2021.12.8

\section{U \\ ANUARI DEL CONFLICTE SOCIAL ...}




\section{Introducción}

Los mitos existen porque son mitos. Están repletos de palabras y personajes fantásticos que nos alucinan o atemorizan según sus melenas y cánticos. Los griegos fueron maestros en ello. Tiresias era ciego y clarividente al mismo tiempo ¿Lo sabía el ex ministro del interior Víctor Pérez? A Tiresias lo dejó ciego la furia de la diosa Atenea a quien Tiresias la sorprendió bañándose desnuda. Ante los ruegos angustiados de la madre de éste, le otorgó el don de adivinar el futuro. El ex ministro del interior, Víctor Pérez, era un Tiresias a medias: ciego, pero incapaz de visualizar el futuro, al menos no con la certeza que lo hacía el mítico adivino quien jamás se equivocaba. Fue ciego en su breve paso por el ministerio, porque no pudo apreciar que la huelga de hambre que los presos políticos mapuche llevaron a cabo por más de 90 días tenía como objetivo que se respetaran los derechos básicos contemplados en la normativa del Convenio 169 de la Organización del TrabajoOIT. Es decir, que se considere su condición de personas pertenecientes a pueblos originarios y puedan cumplir sus penas en sus comunidades donde se respeten sus derechos económicos, sociales y culturales. Este Convenio lo firmó Chile. O sea, no pedían nada especial.

No era clarividente como Tiresias, pues no logró dibujar el futuro en el presente, comprender que al señalar que en el Wallmapu no existen presos políticos y que la violencia proviene de los mapuche, sólo está creando un escenario de guerra que, solamente constituye una provocación más. Es otra pieza de la fragua ideológica del enemigo interno y de una guerra imaginaria.

B ANUARI DEL CONFLICTE SOCIAL ... 


\section{Las peligrosas guerras imaginarias $y$ el enemigo interno mapuche}

Desafortunadamente las guerras inventadas poseen un basamento material que no es imaginario, porque son constituidas por prácticas concretas que involucran torturas, asesinatos, desaparecimientos. Destrucción física y simbólica. Estas guerras imaginarias, diseñadas por la clase dominante, “...están integradas en discursos culturales específicos [ya] que toda violencia organizada implica un código cultural y una articulación colectiva, pero la trama cultural no es en sí misma suficiente para generar y sostener una guerra"1. Por consiguiente, su materialidad, sus prácticas destructivas concretas, son sustentadas en discursos ideológicos y justificadas políticamente, pero agenciadas mediante un aparataje institucional estructurado apriorísticamente para tal fin. La violencia no es prerrogativa de la política, pero siempre es parte integral de ésta, nunca está ausente. Puede ser administrada y racionalizada, mas siempre está presente, porque es una manifestación de poder social; es siempre la disputa entre integración y conflicto, aunque para mantener la integración se apela a la violencia, lo cual conlleva igualmente conflicto. Y esto es lo que, durante todo el año 2020, intentó reproducirse desde el Poder chileno en su relación tensional con el pueblo mapuche: el Continuum histórico de Dominación engarzado por dos negaciones. La primera materializada en el siglo XIX, cuando surgió y se consolidó el Estado-Nación, uninacional y unicultural, negando al pueblo mapuche y culminando con la invasión y usurpación del 95\% de su territorio, origen del conflicto chileno-mapuche actual. Y, la segunda, en la década del setenta con la imposición del modelo neoliberal extractivista por parte de la dictadura cívico-militar y continuada por todos los gobiernos posteriores.

${ }^{1}$ Malesêvic,S. La Guerra y la Teoría Sociológica. “Pro historia”, Año XVIII, núm. 23, jun. 2015. Rosario. Prohistoria Ediciones. p.11

B ANUARI DEL CONFLICTE SOCIAL ... 
Este es el contexto histórico general donde se insertan y concatenan las interrelaciones de Poder y Contra-poder mapuche que, en el último tiempo, han adoptado formas singulares en una constelación surcada por una mega pandemia, un inédito proceso constitucional con participación de los pueblos originarios el cual, por cierto, ha visibilizado al menos dos prístinas posiciones en cuanto al tema autonómico. Todo lo precedente, además, cruzado por ingentes niveles de violencia institucional y de contra-violencia mapuche.

La definición del enemigo interno y la criminalización del movimiento mapuche son parte integral de una misma estrategia política después de todo "el ejercicio de la guerra es la más evidente de las prácticas tanatológicas. Ejercitar, formar y desarrollar una cultura física para matar y morir, es algo abiertamente tanatopolítico"2. Carabineros recibe esta formación, al igual que los efectivos de las Fuerzas Armadas y de la Policía de Investigaciones, independiente que la experiencia histórica y actual demuestra que están más dispuestos a matar que a morir. Además, precisamente por la abisal desproporción de la matriz del poder, su arsenal de violencia es inmensamente superior, violencia legitimada por el Estado de Derecho de una democracia mitificada, pero reconocida como tal por la mayoría. Aunque, siempre en el ámbito de la legitimidad, no lo estén ni la política, ni los políticos, ni los partidos, ni el congreso, ni el gobierno, ni el presidente, ni los ministros, u otras autoridades políticas. $\mathrm{O}$ sea, existe un rechazo generalizado a toda la institucionalidad política. Desde ahí surgió el Estallido y Rebelión de 2019. Paradójico y contradictorio, como la vida y la muerte, porque mientras más uno vive, más se acerca a la muerte y, mientras más uno trata de no morirse, menos se vive. Paradójico porque igualmente se aceptó el "Acuerdo por la Paz" y el itinerario urdido por los partidos

2 Biset. E. "Tanatopolítica". Nombres, Revista de Filosofía, Año XXI, n 26, noviembre de 2012. Córdoba. p. 124

B ANUARI DEL CONFLICTE SOCIAL ...

DOI. 10.1344/ACS2021.12.8 
políticos rechazados por casi todos. En todo caso, lo que importa es que el problema de la violencia no se reduce ni se termina en los ejecutores de la misma, sino que empieza y acaba con los diseñadores de la guerra inventada: el gobierno de la Derecha, en su discurso y su práctica.

\section{Las amenazas de las limpiezas étnicas}

Por lo mismo, el trimestral ex ministro Víctor Pérez sostuvo en sus primeras declaraciones que su prioridad sería el conflicto en La Araucanía "porque los chilenos merecen vivir en paz y tranquilidad. Alejaremos a los violentos para solucionar los problemas"3. Y los mapuche, ¿no merecen vivir en paz? Al parecer no es el caso. Las palabras de Pérez, enceguecido, más que ciego, sin duda propulsaron los deleznables sucesos de Curacautin, Victoria, Ercilla y Traiguen, dónde grupos de civiles de manera violenta y artera atacaron, con la complicidad de Carabineros, a comuneros mapuche que habían ocupado las dependencias de las municipalidades de estas ciudades en solidaridad con los presos en huelga de hambre. Esta incitación al odio y al enfrentamiento entre pueblos tampoco es casualidad. Siempre ha existido el racismo en La Araucanía, latente y patente, pero en los últimos 20 años las confrontaciones más ostensibles han sido entre mapuche y agentes del Estado, guardias de seguridad de las forestales, agricultores y algunos grupos paramilitares de ultraderecha. Siempre la violencia proviniendo de estos grupos y la autodefensa de los mapuche. Ahora se está incentivando y manipulando el odio y accionar interracial entre pueblos y esto puede tener horrendas consecuencias. Sin embargo, esto tampoco es nuevo. Al referirse a la mal llamada Pacificación de la Araucanía, Adolfo Millabur, ex alcalde de Tirúa hace ya hace 30 años indicó que

3 https://www.pauta.cl/politica/cambio-de-gabinete-interior-victor-perez-udigonzalo-blumel-evopoli

B ANUARI DEL CONFLICTE SOCIAL ...

DOI. 10.1344/ACS2021.12.8 
"nuestro Kosovo fue la Pacificación de La Araucanía...no se dice que fue una matanza, una limpieza étnica, como hoy sucede en Kosovo. Aquí, en aquella época, se hizo eso mismo. Pero este país olvida su historia, niega su memoria. Si se lograra hablar de estas cosas a los niños, tendríamos un país mucho más preocupado y sensibilizado sobre el problema mapuche. Se ha producido una enajenación masiva, muy bien pensada por la estructura de poder de este país, destinada a ocultar y deformar el problema mapuche para desconocer así los derechos de nuestro pueblo"4.

Solo un par de años después, luego que su casa en la comunidad Pascual Coña en Lleu- Lleu fuera asaltada y acribillada por Carabineros, la comunera Elba Santi señalaba que "en cualquier momento puede haber una matanza, porque lo que quiere hacer el gobierno es una limpieza étnica" 5 . Fue en el gobierno de la Concertación y, por cierto, no es dable suponer que esa era la estrategia política, más bien la continua asimilación del pueblo mapuche. Lo de Víctor Pérez, quien no se mandaba solo evidentemente, es algo distinto. El presidente Piñera y todos sus asesores, políticos y militares, han diseñado una estrategia de guerra de baja intensidad en el Wallmapu. Así, se configura el oráculo de un gobierno agónico que requiere de victorias y, como la muerte tiene ojos de fuego, tal vez pensaron que el ex alcalde pinochetista y sempiterno parlamentario les podía coadyuvar a iluminar el futuro y solucionar definitivamente el "problema mapuche". Después de todo, Tiresias nunca erraba en sus predicciones; claro porque el mítico Tiresias vio a Atenea desnuda, le costó la vista, pero se convirtió en adi-

4 Tricot, Tito (2014). Palabras de Tierra: Crónicas de la Resistencia Mapuche. Ceibo Ediciones. Santiago de Chile. Nuestro Kosovo fue la Pacificación de la Araucanía. p. 120

${ }^{5}$ Ibidem. Limpieza étnica en territorio mapuche, p220

B ANUARI DEL CONFLICTE SOCIAL ...

DOI. 10.1344/ACS2021.12.8 
vino y esto ni Pérez ni Piñera lo son, por ello el conflicto no se soluciona aún.

\section{La "solución" policial a un conflicto político o la incapacidad de entender la causa del mismo}

Es más, se ha intensificado ${ }^{6}$, aunque -como ha sucedido durante la reemergencia del movimiento mapuche autonomista en Lumako en 1997- se ha producido un desplazamiento intercomunitario en el accionar, así como también en las formas de combate, en los discursos, en la conformación organizacional y, en consecuencia, en los liderazgos y estrategias políticas. Simultáneamente, se acrecentó la represión policial, la cual constituye una sistemática política de racionalización de recursos cuyo objetivo es neutralizar o aniquilar a al movimiento mapuche. La Unidad de Coordinación Estratégica en la Macrozona Sur, creada en 2018 es un componente esencial de esta guerra de baja intensidad, pero de alta peligrosidad. Acorde al otrora ministro del interior, André Chadwick. Posteriormente destituido- La unidad tiene "la misión de apuntar a tres focos delictuales específicos. En primer lugar, la violencia rural y las acciones terroristas; en segunda instancia, el crimen organizado para el robo de madera y el abigeato; y por último, el narcotráfico y microtráfico" ". Huelga decir que aquí no existe sub-texto alguno, simplemente se trata de unificar a las policías para "neutralizar" al movimiento autonomista mapuche en las Regiones del Biobío, La Araucanía, Los Ríos y Los Lagos. Y también a los chilenos, por eso lanzaron al joven al joven Anthony Araya al río Mapocho desde el Puente Pio Nono en Santiago, no obstante, el ministro del interior, el mismo Pérez y su gobierno declararon sin vergüenza que

${ }^{6}$ Ver, por ejemplo, en este mismo anuario el capítulo Rojas Pedemonte, Nicolás; Gálvez, Diego; Solís, Ariadna. "La protesta mapuche durante la pandemia".

${ }^{7}$ https://www.interior.gob.cl/noticias/2018/10/26/ministro-del-interior-inaugurala-unidad-de-coordinacion-estrategica-de-la-macrozona-sur/

B ANUARI DEL CONFLICTE SOCIAL ...

DOI. 10.1344/ACS2021.12.8 
"el gobierno respalda la necesaria y fundamental labor de Carabineros, en cumplimiento de su mandato constitucional de resguardar el orden público y la seguridad ciudadana de todas las personas, dentro del marco de sus protocolos y la ley, y siempre con pleno respeto a los Derechos Humanos de todos"s.

Al poco tiempo el ministro hubo de renunciar, luego de que la cámara de diputados aprobara la acusación constitucional en su contra. Tampoco lo vio venir. Su abogado defensor, Gabriel Zaliasnik, sostuvo en parte de su alocución que "es el momento de mirarnos todos a los ojos". Más aún, el abogado penalista escribió en enero de este año acerca del campo de concentración de Auschwitz indicando que lo sucedido debería servir "para mirar la historia a los ojos...". Esa fijación con metáforas oculares cuando Carabineros ya había destruido la vista y la vida a centenares de jóvenes con balines o lacrimógenas es, por decir lo menos, repudiable. El ministro fue ciego, sí, menos todavía profetizó el futuro del conflicto en territorio mapuche o el suyo propio. Prometió el diálogo, pero de inmediato negó la existencia de presos políticos mapuche e ignoró la luenga huelga de hambre llevada a cabo por éstos, incluido el machi Celestino Córdova, quien estuvo al borde la muerte. Aunque cuando los camioneros, coordinados por la Confederación Nacional de Transporte de Carga, iniciaron un paro nacional en medio de la pandemia del Coronavirus, inmediatamente dialogó con ellos. los gremios de los camioneros recurrieron tanto a la amenaza y a la acción, bloquearon las carreteras, provocando desabastecimiento y temor en la población. Ellos, mientras tanto, se iban de fiesta en plena vía pública sin que el ministerio del interior se preocupara de ello. La conceptualización y práctica del diálogo democrático es irredargüiblemente unilateral y de evidente contenido clasista, racista y colonial ${ }^{9}$. Asimismo, la violencia política es una posibilidad de

8 https://www.infogate.cl/2020/10/03/ministro-del-interior-ante-nueva-crisis-porproceder-de-carabineros-en-caso-mapocho-dice-que-los-protocolos-de-carabineroshan-cambiado-en-relacion-al-anopasado/

$9 \mathrm{El}$ acuerdo con los camioneros incluyó una Inversión de $\$ 5.600$ millones en infraestructura policial, aumento de los medios aéreos en la zona, el establecimiento de una coordinación especial de información de inteligencia y de una Prefectura

B ANUARI DEL CONFLICTE SOCIAL ...

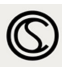

DOI. 10.1344/ACS2021.12.8 
conflicto disponible para clases, grupos sociales, étnicos o de otra índole, pero por, sobre todo, un modo de ser de la política; un modo relacional de carácter estructural y así lo entendieron el gobierno y los camioneros. Por su parte, en el marco del conflicto territorial en el Wallmapu.

"para la clase dominante chilena es una arquitectura de control necesario, para el pueblo mapuche es un entramado de dominación injusto; para el primero es violencia legítima y la ha naturalizado mediante diferentes mecanismos culturales, ideológicos, educacionales. Para el segundo, la violencia política es equivalente a discriminación, asimilación, usurpación territorial, racismo, aunque, precisamente producto de la mencionada naturalización de la violencia y su disimulo social, una parte del pueblo mapuche pueda haberse aculturado o integrado marginalmente a la sociedad chilena. Incluso esa aculturación tiene una génesis políticamente violenta, por consiguiente, no es natural, ni siquiera inducida, sino que forzada por procesos de guerra, ocupación militar, arreduccionamiento y emigración impuesta"10.

\section{El denso y violento peso de la institucionalidad chilena y sus fisuras}

En el contexto mencionado anteriormente, el Estado es el concentrador principal de la violencia, aunque esta no es "naturalmente, ni el medio normal ni el único medio de que el Estado se vale, pero sí es su medio específico"11 del cual se vale para generar las condiciones necesarias de la edificación y generación del modelo neoliberal y del sistema capitalista. El Acuerdo por la Paz y una Nueva Constitución es una

Macrozonal Sur de la PDI, entre otras medidas.

10 Tricot, Tito (2017) Aukan, violencia histórica chilena y resistencia mapuche.Ceibo Ediciones. Santiago de Chile. p. 35

11 Weber,Max. El político y el científico. Alianza Editorial.Madrid,. 1979. p.83

B ANUARI DEL CONFLICTE SOCIAL ... 
clara manifestación de la capacidad de la clase política, con todos sus matices y claroscuros, de transformar una situación defensiva y de fragilidad de la correlación de fuerzas en una de superación de una crisis a mediano plazo. Si bien es cierto nada hubiese sido posible sin el Estallido social y la subsecuente rebelión popular, lo concreto es que, es el itinerario emanado desde el poder el que comenzó a implementarse desde 2020.

Los movimientos sociales son actores colectivos heterogéneos, los cuales pueden o no transformarse en sujetos de cambio histórico con conciencia y sentido de ello. Ello, pienso, se perdió en las profundidades de las oquedades de las fisuras desde donde surgió el propio movimiento. Es decir, estremeció las relaciones del poder, la base de este, mas no la solidez de la capacidad de recuperación de la clase política, económica, ideológica, militar y cultural. Inclusive, algunos autores han calificado al movimiento únicamente como un movimiento de consumidores $^{12}$. La teluridad y deflagración del Estallido fue disuelto, al menos temporalmente, por dicho Acuerdo.

Los mitos existen, como dijimos, porque son mitos. Están repletos de palabras y personajes fantásticos que nos alucinan o atemorizan. La clase política sintió el poder del pueblo, indudablemente, sin embargo, se recuperó y golpeó con todo el peso de la institucionalidad en medio de la madrugada para que la Calle estuviese medio dormida, aletargada, desconcertada, aunque siguió movilizada por un tiempo más, pero ya el debate se había constitucionalizado. La misma Calle se constitucionalizó, o se restó del debate o comenzó un nuevo proceso de reorga-

12 Venegas Caro, Diego (2019). Lucha de clases o revuelta de consumidores? Aportes para un análisis de coyuntura de la revuelta de Octubre del 2019. Revista Historia en Movimiento. Año v | Número 5 | octubre 2020

B ANUARI DEL CONFLICTE SOCIAL ...

DOI. 10.1344/ACS2021.12.8 
nización territorial, tal vez con una nueva y renovada impronta. La democracia mitificada chilena había triunfado una vez más. Es que los griegos fueron maestros en ello también. Tiresias era ciego y clarividente al mismo tiempo y la clase política lo fue en parte.

Continuó la represión al pueblo mapuche para restaurar el denominado Orden Público y el Estado de Derecho con permanentes llamados al envío de las Fuerzas Armadas para apoyar la labor policial, particularmente, en condiciones de Pandemia y control -supuestamente subversivo- en la macrozona sur ya expuesta con antelación. De ahí los intentos de introducir legislación para endurecer las penas para distintos delitos cometidos en el Wallmapu. Estos supuestos delitos, como ha sido comprobado en innúmeras oportunidades, son productos de montajes donde los imputados pasan largos periodos en prisión para luego ser liberados sin cargo alguno. Aun así, en el discurso, y como consecuencia de la rebelión de octubre de 2019, muchos políticos no pudieron permanecer del todo diferentes ante lo que sucedía en relación a los pueblos originarios. Inclusive el senador Felipe Harboe, quien fue subsecretario del Interior de los gobiernos de Michelle Bachelet y Ricardo Lagos, donde fueron asesinados mapuche, declaró:

"Quiero humildemente pedir perdón, perdón por los errores que cometí en el ejercicio de mis funciones y por la incapacidad como dirigente político y como servidor público de no haber logrado y no haber aportado definitivamente a una inclusión real de los pueblos originarios" $"$.

Fue en el mes de los gatos, hermosos animales que te acarician y se dejan acariciar hasta que ellos deciden, después simplemente se van

13 https://www.biobiochile.cl/noticias/nacional/chile/2020/08/06/harboe-pidio-disculpasgestion-gobiernos-anteriores-respecto-conflicto-la-araucania.shtml

B ANUARI DEL CONFLICTE SOCIAL ... 
¿Serán sinceras las palabras de Harboe? Puede que la violencia no sea connatural al ser humano, o que la desarmonía forme parte del destino humano ${ }^{14}$; la violencia puede ser una condición de posibilidad para resolver problemas sociales, pero también puede ser -como en el caso del pueblo mapuche actual- un recurso de resistencia. Puede ser palmaria o relativamente oculta o racionalizada. Pero siempre es parte de la política, ello es claramente reflejado en la discusión por los escaños reservados para los pueblos originarios. En este ámbito se dieron varios elementos donde Tiresias hubiese tenido que utilizar todas sus facultades clarividentes para desentrañar, primero, los vericuetos de los increíbles rincones de Valparaíso para comprender cómo finalmente se revolvió el problema de los escaños reservados.

\section{La increíble ¿o no? Disputa por los escaños reservados para los Pueblos Originarios}

El proceso no estuvo exento de dificultades, sino que demostró el carácter colonial y, concurrentemente, la ignorancia de los parlamentarios chilenos y de los políticos en Chile, como se lo hicieron saber varias organizaciones de pueblos originarios que asistieron al congreso a exponer su opinión acerca de los escaños reservados, lo que de suyo demuestra una relación colonial de poder asimétrica. Lo concreto, es que en este prolongado proceso y sucesión de eventos

"el plebiscito sobre la nueva Constitución tuvo lugar antes que se resolviera la fórmula de representación indígena, lo que implicó problemas obvios: quienes participaron del plebiscito por la Convención no sabían exactamente qué mecanismo estaban apoyando en términos de representación indígena. Por otra parte, la fórmula de escaños reservados se resolvió apenas a poco más de un mes de que cerrar el

${ }^{14}$ Moriconi, Marcelo (2013). Ser violento. Los orígenes de la inseguridad y la víctima cómplice. Capital intelectual. Buenos Aires

B ANUARI DEL CONFLICTE SOCIAL ... 
registro de candidatos a la Convención. Por lo tanto, los representantes indígenas a bancas reservadas tuvieron significativamente menos tiempo para inscribirse que el resto de la población del país. Además, la fórmula escogida no recogió las demandas de las organizaciones mapuche en aspectos tales como la definición del padrón de habilitados a votar por los escaños, el número de bancas reservadas y su distribución, entre otros" ${ }^{\prime 15}$.

De hecho, en un país profundamente machista como el chileno, la problemática de la paridad de género fue resuelta con mayor celeridad, indudablemente debido a la lucha del movimiento feminista y a los cambios societales derivados del mismo. Sin embargo, no ocurrió igual con los pueblos originarios. Lo que pasa es que en Matemáticas puede que dos más dos sean cuatro, pero en el Congreso chileno suman y restan como quieren cuando se trata de los pueblos originarios. O, mejor dicho, siempre se llega a cero, porque el tema de los escaños reservados para la Convención Constitucional no es asunto de Matemáticas, es Racismo. Y punto. Lo demás es simplemente lírica. Aunque pareciera que los números y las palabras no son compatibles, la verdad es que sí son útiles para enredar las cosas, que es otra forma de decir política. ¿Por qué no? Mientras tanto nos dicen con la mirada entornada que todos anhelan profundamente que "nuestros" pueblos originarios sean partícipes de esta Convención que debe ser lo más pluralista posible.

¿Pero no iba a ser tan pluralista, cómo entonces la clase política se apropió de los pueblos originarios y ahora son "nuestros", o sea son chilenos? Por ende, ya apriorísticamente se excluye la posibilidad de

${ }^{15}$ Bidegain, G. \& Tricot, V. (2021). Escaños reservados para los mapuche en la Convención Constitucional: Una rendija institucional gracias a la revuelta. Anuario Del Conflicto Social, (12), e-36979. https://doi.org/10.1344/ACS2021.12.1

B ANUARI DEL CONFLICTE SOCIAL ... 
que se pueda construir un Estado plurinacional. Y, además, es tal la profundidad de sus deseos que ahí ocultan, en aquellos oscuros laberintos soterrados, una ideología racista y colonial, cubriéndola con un manto de números que para los chilenos parecieran carecer de importancia. Por eso, cuánta razón tiene la lingüista mapuche Jaqueline Caniguan cuando señala que "si a los chilenos se les ha engañado diez veces, a los pueblos originarios se nos ha engañado cien”. ¡Hay que tener ojo de cóndor!, dice. Un ojo agudo, preciso, siempre abierto; un ojo que jamás duerme porque cuando se descuida, la clase política, de la noche a la mañana, le puede cambiar la Asamblea Constituyente por una Convención Constitucional. Del mismo modo que en aquel breve momento en que miró hacia el lado equivocado, el gobierno dijo que los Escaños Reservados serían 15 y no más. La oposición hizo como que se oponía, pero en realidad no tuvo el coraje de hacerlo.

Los pueblos originarios, donde algunos aspiran a tener paridad de género de acuerdo a su cosmovisión, representación en proporcionalidad demográfica, es decir al menos el 12,8 de la población del país, o escaños supernumerarios, sencillamente no cuentan, pues no es un problema de matemáticas, sino que de racismo, de política, de poder. Y el poder no lo tienen ni los mapuche, los diaguita, los aymara o los likan antay ni ninguno de los diez pueblos originarios y afrodescendientes que habitan estos territorios. Lo tienen los que negociaron el Acuerdo por la Paz en noviembre de 2019, la Paz de una Guerra inventada. Los que redactaron la Ley 21.200 en diciembre de ese mismo año que diseñó todo el itinerario constitucional.

Para el último se dejó a los indios. Claro, total tienen paciencia de indio. Empero, no es esa la razón, quizás el Estado esperaba que los pueblos originarios no participaran en el plebiscito -o participara mucho menos gente- o que simplemente no fueran parte de la Convención, aun con todas las limitantes que esta posee. Quizás algunos chilenos no pueden aceptar que su blancura no es tan blanca, que los

B ANUARI DEL CONFLICTE SOCIAL ... 
originarios no son ellos. Que los pueblos originarios estaban antes, que quizás deban asumir que los escaños reservados deberían ser para los chilenos. Pero no son todos los chilenos, es el Estado, es la clase política, por ello esto no es un problema de matemáticas, sino que de racismo. No todos los integrantes y organizaciones de los pueblos originarios creen o quieren participar en el proceso constitucional, ya que son muy diversos, pero es dable suponer que al ojo del cóndor se le han adicionado sus colosales alas y está volando cada vez más bajo. Y todos sabemos de qué se alimenta el cóndor.

Sea como fuere, se determinó la representación indígena en la Convención Constitucional mediante 17 escaños reservados, siendo 7 de ellos para el pueblo mapuche, demográficamente mayoritario en el país. Uno podría argumentar que participación no equivale a representación o, incluso menos a autonomía, no obstante, los pueblos originarios que se han inclinado legítimamente por esta opción así lo piensan. Adicionalmente, buscan trazar el sendero hacia la plurinacionalidad. Para Adolfo Millabur, ex alcalde de Tirua quien renunció a su cargo para ser candidato a constituyente, la plurinacionalidad

"es una estrategia política. No creo que la plurinacionalidad en sí va a permitir resolver la relación de desigualdad o de opresión, o de sometimiento que el Estado siempre ha tenido con los pueblos originarios. Yo creo que podemos correr el cerco. Mientras la plurinacionalidad permitirá discutir de igual a igual, porque cuando uno habla de "nación/nacionalidad" pone en cuestión el concepto de nación monocultural. Entonces se les mueve el piso, a mi entender, a los intelectuales, a los políticos, a los que toman decisiones políticas, finalmente. Los sacas de su comodidad de relato permanente que es: Estado igual a nación. Y uno cuando revisa la propia Constitución actual, lo asimila así. En todo el articulado no se pregunta de que haya otras naciones, sino que simplemente lo asimila de esa manera. Entonces, tú les cambias el estadio de diálogo y les mueve un poco las aguas para poder abrir espacios de cuestionamiento del estatus. Ahí entra el otro elemento que yo creo que es

\footnotetext{
B ANUARI DEL CONFLICTE SOCIAL ...
} 
interdependiente, no sirve solo hablar de plurinacionalidad a solas, sino que también necesariamente hay que incluir inmediatamente el concepto de interculturalidad. Interculturalidad desde el punto de vista crítico, no desde el punto de vista funcional porque el que más se conoce en Chile como relato es funcional, donde se traduce al mapudungun a conceptos occidentales, por ejemplo"16.

Apunta, al mismo tiempo, su convencimiento de que no se puede permanecer al margen de este espacio en el cual se puede incidir, y si la influencia es solo simbólica, entonces los historiadores escribirán de esto como un fracaso. Pero hay que estar ahí. ¿Aparecerá Tiresias en algún rincón del Wallmapu? No lo sabemos, pero sí que, por su parte, desde otro prisma, Alvarado Lincopi afirma que

"el proyecto plurinacional puede permitir reconfigurar el entramado social, político e institucional heredado desde siglo XIX; ostenta un potencial corrosivo contra el peso señorial. Es la propuesta desde los pueblos indígenas para abrir el siglo XXI, con toda la sociedad a cuestas, buscando superar el poderío que sostiene el relato blanqueado de la nación, porque esta no se trata únicamente de una narrativa, sino que ha sostenido privilegios por décadas, siglos"17

Efectivamente no es una narrativa únicamente, de lo contrario sería una novela, una mala poesía tal vez -para el pueblo mapuche-, sino que tiene un cimiento material de dominación, un campo que lleva implícito un metarrelato universalizante, una comunidad imaginada: la nación chilena, elaborada e impuesta desde el poder y para el poder. Por ende,

16 Millabur, Adolfo (2020) "La plurinacionalidad es un concepto para entendernos y encontrarnos con el otro que no es mapuche. Wallmapu. Ensayos sobre Plurinacionalidad y nueva Constitución. Pehuén y CIIR. Santiago de Chile. 222

17 Ibidem, Alvarado Lincopi, Claudio (2020) Una razón antropofágica para una constituyente plurinacional. De la nación blanqueada a la comunidad política abigarrada.

B ANUARI DEL CONFLICTE SOCIAL ...

DOI. 10.1344/ACS2021.12.8 
uno pensaría que un Estado plurinacional requiere, por definición, la convivencia simétrica entre naciones y la desjerarquización de sujetos colectivos. Alvarado, y por extensión lógica, uno supone, los que aceptaron ser candidatos y candidatas a la convención, creen en ello. En otras palabras, "la plurinacionalidad como una potencia, una que posibilite el encuentro y la convivencia de diversas trayectorias históricas en la misma comunidad política que es Chile, superando con ello el viejo guion nacional de porfiada homogeneidad blanquecina y elitaria"18. Se trata, entonces, de influir en la textura del Estado, de indigenizarlo, plurinacionalizarlo, interculturalizarlo. Es, de alguna forma, una gran empresa de pedagogía que busca cambiar la balanza del poder, que este se escriba, narre y practique de manera diferente. Porque, se argumenta,

"El Estado Plurinacional permite avanzar en la hegemonía discursiva y para que sea política deben posicionarse parlamentarios emergidos desde el movimiento mapuche. La negativa a los escaños reservados aleja esa posibilidad de repensar un nuevo tipo de democracia ... también permitiría iniciar políticas que desmantelaran las estructuras que han permitido las diferencias entre la sociedad indígena y la no indígena" $" 19$

En una posición diametralmente opuesta se encuentran otras organizaciones mapuche las cuales, operando básicamente en el Wallmapu como la Coordinadora Arauco-Malleco, Weichan Auka Mapu, El Consejo de Todas las Tierras, La Franja Territorial Lafkenche u otrasreivindican la resistencia al Estado y a las forestales principalmente; la autonomía territorial de facto, el control territorial y, por tanto, rechazan participar en la Convención Constitucional. Para la CAM, por

${ }^{18}$ Ibid. P.98

19 https://www.ciperchile.cl/2019/12/20/estado-plurinacional-el-debatemapuche-actual/

B ANUARI DEL CONFLICTE SOCIAL ... 
ejemplo, el Estado es una forma de ordenamiento socio-político moderno occidental, por consiguiente, el participar de esta Convención constituye otro modo de institucionalización o asimilación del pueblo mapuche a las estructuras coloniales chilenas, alejándose de su política de liberación nacional. De hecho, Héctor Llaitul, werken de la CAM, ha planteado que "los mapuche vivimos bajo un estado de ocupación militar permanente. Es la expresión más clara del Estado colonial de cual debemos liberarnos"20. Para la CAM la Convención es irrelevante, esta, como otros segmentos del Movimiento Mapuche Autonomista prosiguieron la disputa territorial en las comunidades: esa es su Calle. Como lo fue para el movimiento social de octubre de 2019 en Chile. Para el Consejo de Todas la Tierras, la Convención es la domesticación de sectores del movimiento mapuche y de sus demandas y, por ello, su estrategia es la conformación de un autogobierno mapuche. Evidentemente, ni la CAM ni ninguna otra organización autonomista representan a todo el pueblo mapuche, no obstante, sí en conjunto con otras expresiones movimentales han podido ejercer control territorial en numerosas comunidades del Wallmapu, posicionando el discurso y la práctica autonómica factualmente. Es la Contra-violencia, la Contra-negación, el Contra-Poder mapuche en acción. El sendero hacia la libredeterminación, una de cuyas expresiones concretas es la autonomía, pasa por la (re) construcción del Mundo y del País mapuche y esto la distancia del Estado y, por cierto, de la Convención. El mismo Llaitul, antes que siquiera se vislumbrara un Estallido o Convención alguna, manifestó que

"el Weichan no es ajeno al Mundo Mapuche hoy día; si no creemos en los weichafe, o en el Weichan, tampoco creemos en las machi. Las

${ }^{20} \mathrm{https} / /$ radio.uchile.cl/2020/06/24/hector-llaitul-el-gobierno-esta-tratando-deapagar-el-fuego-con-bencina/

B ANUARI DEL CONFLICTE SOCIAL ... 
machi tienen el espíritu de los antiguos, los pu longko, sus pellü (106), sus espíritus, nos van a dar orientaciones [en la lucha]. Lucha que tiene un carácter de descolonización ideológica, cultural, política en la perspectiva etnocultural propia, y política después, para la reconstitución nacionalitaria, que es el gran proyecto nuestro que se va a lograr con la restitución territorial y derechos políticos: con la autonomía" (Llaitul, entrevista personal, 2016).

Para mayor precisión, en plena pandemia y en el día del We Tri Pantu Año Nuevo mapuche- cuando el gobierno -una vez más- anunció que enviaría a personal de las Fuerzas Armadas a territorio mapuche, Llaitul indicó que

“ya llevamos más de dos décadas de lucha territorial y política, hay una experiencia en la autodefensa y la resistencia. De hecho, ya estamos preparados para un enfrentamiento armado. Ya resurgió el weichan (guerra mapuche) y nuestros weichafe ya nos hemos convocado, con consciencia y con valor. Hoy contamos con capacidad militar para la defensa de lo recuperado y para seguir avanzando. Nosotros vivimos acá, conocemos nuestro territorio y tenemos la convicción en nuestras mentes y corazones; pero es la fuerza espiritual la que nos dará el newen necesario para resistir y vencer"21.

\section{Conclusiones: E1 Futuro está atrás}

Los mitos existen porque son mitos, para que jamás olvidemos que a Tiresias lo dejó ciego la furia de la diosa Atenea, a quien Tiresias la sorprendió bañándose desnuda. Ante los ruegos angustiados de la madre de éste, la Diosa le otorgó el don de adivinar el futuro. El ministro Víctor Pérez, enviado plenipotenciario del gobierno de Piñera, fue ciego, pero no pitoniso, prosiguiendo con las políticas represivas de siempre demostrando la incapacidad del Estado de entender un con-

${ }^{21}$ Ibidem.

B ANUARI DEL CONFLICTE SOCIAL ... 
flicto centenario. No pudo vislumbrar que la solución no es militar, que el diseño de una guerra de baja intensidad solo generará más violencia, resentimiento, y reproducción de un Continuum histórico de Dominación que hace tiempo dejó de ser identitario.

Este no es un conflicto entre mapuchidad y chilenidad. Cuando nos remitimos a autonomía y libredeterminación, a resistencia, violencia política, sabotajes, plurinacionalidad, pluriculturalidad o interculturalidad, estamos hablando de una interpelación profunda al Estadonación decimonónico chileno. A un problema estructural. Dicen los antiguos que el futuro está atrás, quizás así sea y por ello para entender lo acaecido y todas las posibles interrelaciones entre las políticas represivas del Estado, la matriz colonial que obstaculizó la materialización de los Escaños reservados; exacerbó y manipuló las contradicciones étnicas en el Wallmapu, así como consolidó una narrativa racista, nacionalista y colonialista, hay que hurgar en la historia reciente, cuando pocos se imaginaban que estaríamos hablando o escribiendo sobre estos temas. Y en la memoria distante, la del mapuche, no la de Tiresias quien vio a Atenea desnuda y le costó la vista, pero que, al fin y al cabo, es tan solo un mito.

\section{Referencias}

Alvarado Lincopi, C. (2020). Una razón antropofágica para una constituyente plurinacional. De la nación blanqueada a la comunidad política abigarrada. En D. Namuncura et al., Wallmapu. Ensayos sobre Plurinacionalidad y nueva Constitución (pp.89-104). Pehuén y CIIR.

Bidegain, G. y Tricot, V. (2021). Escaños reservados para los mapuche en la Convención Constitucional: Una rendija institucional gra-

B ANUARI DEL CONFLICTE SOCIAL ... 
cias a la revuelta. Anuario Del Conflicto Social, 12, e-36979. https://doi.org/10.1344/ACS2021.12.1

Biset, E. (2012). Tanatopolítica. Nombres, 26, 245-274.

Malesêvic, S. (2015). La Guerra y la Teoría Sociológica. Probistoria, 23, 3-19.

Millabur, A. (2020). La plurinacionalidad es un concepto para entendernos y encontrarnos con el otro que no es mapuche. En D. Namuncura et al., Wallmapu. Ensayos sobre Plurinacionalidad y nueva Constitución (pp. 221-232). Pehuén y CIIR.

Moriconi, M. (2013). Ser violento. Los orígenes de la inseguridad y la víctima cómplice. Capital intelectual.

Tricot, T. (2020). La Rebelión en Valparaíso: Testimonios Entre Lineas. Kütral Ediciones.

Tricot, T. (2017). Aukan, violencia bistórica chilena y resistencia mapuche. Ceibo Ediciones.

Tricot, T. (2014). Palabras de Tierra: Crónicas de la Resistencia Mapuche. Ceibo Ediciones.

Tricot, V. y Bidegain, G. (2021). Un año más de desencuentros: participación y política institucional mapuche en 2019. Anuario del Conflicto Social, 11 54-74. https://doi.org/10.1344/ACS2020.11.5

Venegas Caro, D. (2019). ¿Lucha de clases o revuelta de consumidores? Aportes para un análisis de coyuntura de la revuelta de Octubre del 2019. Revista Historia en Movimiento, 5, 66-72.

Weber, M. (1979). El político y el científico. Alianza Editorial.

B ANUARI DEL CONFLICTE SOCIAL ... 


\section{Linkografía}

https://www.pauta.cl/politica/cambio-de-gabinete-interior-victorperez-udi-gonzalo-blumel-evopoli

https://www.interior.gob.cl/noticias/2018/10/26/ministro-delinterior-inaugura-la-unidad-de-coordinacion-estrategica-de-lamacrozona-sur/

https://www.infogate.cl/2020/10/03/ministro-del-interior-antenueva-crisis-por-proceder-de-carabineros-en-caso-mapochodice-que-los-protocolos-de-carabineros-han-cambiado-enrelacion-al-anopasado

https://www.biobiochile.cl/noticias/nacional/chile/2020/08/06/har boe-pidio-disculpas-gestion-gobiernos-anteriores-respectoconflicto-la-araucania.shtml

https://www.ciperchile.cl/2019/12/20/estado-plurinacional-eldebate-mapuche-actual/

https://radio.uchile.cl/2020/06/24/hector-llaitul-el-gobierno-estatratando-de-apagar-el-fuego-con-bencina/

https://www.latercera.com/politica/noticia/diputados-udi-proponenal-gobierno-creacion-de-penales-especiales-y-especificos-parapresos-de-pueblos-

originarios/WAYP75JUOVAQJAYJHW2LSSKMHQ/?outputType=a $\underline{\mathrm{mp}}$

https://www.biobiochile.cl/noticias/nacional/chile/2020/08/06/har boe-pidio-disculpas-gestion-gobiernos-anteriores-respectoconflicto-la-araucania.shtml

B ANUARI DEL CONFLICTE SOCIAL ... 


Este texto está protegido por una licencia Reconocimiento Creative Commons 4.0.
Usted es libre para Compartir — copiar y redistribuir el material en cualquier medio o formato- y Adaptar el
documento - remezclar, transformar y crear a partir del material— para cualquier propósito, incluso
comercialmente, siempre que cumpla la condición de:
Atribución: Usted debe reconocer el crédito de una obra de manera adecuada, proporcionar un enlace a la
licencia, e indicar si se han realizado cambios. Puede hacerlo en cualquier forma razonable, pero no de forma
tal que sugiera que tiene el apoyo del licenciante o lo recibe por el uso que hace.
$\underline{\text { Resumen de licencia - Texto completo de la licencia }}$

B BNUARI DEL CONFLICTE SOCIAL ... 